\title{
INDUCTIVE LOOP SYSTEM EQUTVALENT CIRCUIT MODEL
}

\author{
Milton K. Mills
}

\section{U. S. Department of Transportation Federal Highway Administration Washington, D. C.}

\section{Abstract}

This paper describes the development and application of an equivalent circuit model and computer program to calculate the apparent self inductance and quality factor versus frequency of square, rectangular, quadrupole, and circular loops of round wire buried in a roadway. The effect of transmission lines and matching transformers between the loop in the roadway and roadside vehicle detector electronics is included in the model. The capacitance between the loop conductors and surrounding pavement material is shown to have a major effect on the magnitude of the loop's apparent self inductance.

Inductive loop detectors are presently used in most actuated and computer controlled traffic surveillance systems. The design of the loop's size and shape, and number of turns of wire should provide adequate vehicle detection sensitivity and prevent the transmission line from reducing sensitivity. The magnitude of inductance seen by the detector electronics must be in a range specified by the detector manufacturer. The computer program calculates the loop apparent inductance and quality factor versus operating frequency $(20-60 \mathrm{kHz})$ for a selected loop size, shape, conductor size, number of turns, turn spacing, slot width, pavement loss tangent, and slot sealant material dielectric constant.

\section{Introduction}

The inductive loop detector system is comprised of a buried loop of round wire in the roadway pavement which is connected with a transmission line to roadside vehicle detector electronics. When a vehicle is sensed by the loop, a small decrease in loop inductance is detected by the detector electronics. Since the series inductance of the transmission line decreases the loop inductance change available to the detector electronics, the loop inductance should be larger than the transmission line series inductance. The loop inductance can be increased by winding additional turns to the loop and/or adding a transformer between the loop and transmission line. The frequency range of typical vehicle detector electronics is $20 \mathrm{kHz}$ to $60 \mathrm{kHz}$. The inductance seen by the vehicle detector electronics can change significantly versus frequency if too many turns are used on the roadway loop because of loop capacitance. An equivalent circuit model of the inductive loop system was developed and programmed on a computer. The computer program allows inductive loop system designers and maintenance technicians to calculate the loop system inductance and quality factor as a function frequency, wire gauge size, wire spacing, etc.

The equivalent loop system model is comprised of a roadway inductive loop model, a transformer model, and a transmission line model. The calculation of the self inductance of square, rectangular, and quadrupole loops is described in previous papers $[1,2]$. King [3] describes the calculation of the self inductance of circular loops. This paper includes the calculation of the internal and external capacitance of such loops to determine high frequency performance. A wide band transformer model is used. The transmission line model uses a complex characteristic impedance. All equations used in the loop computer program are included in this paper.

\section{Loop Capacitance Theory}

\section{Internal Loop Capacitance}

The capacitance between loop turns was calculated using a low frequency, multi-layer, transformer model [4]. This model assumes uniform flux coupling through the loop turns with minimum leakage flux. Figure 1 illustrates the capacitance between two adjacent isolated loop turns.

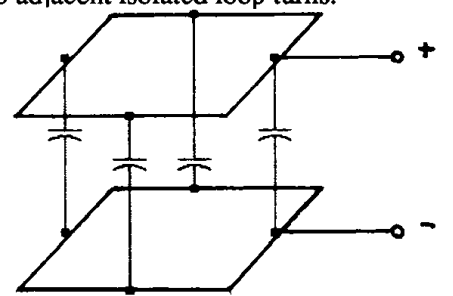

FIGURE 1. CAPACITANCE BETWEEN ADJACENT ISOLATED LOOP TURNS.

The loop is comprised of parallel transmission lines with a capacitance [5] per unit length, $C^{\prime}$, given by

$$
C^{\prime}=\frac{\left(\varepsilon / \varepsilon_{\mathrm{o}}\right) \times 10^{-9}}{36 \cosh ^{-1}(D / 2 \mathrm{a})}
$$

where

$$
\begin{aligned}
& C^{\prime}=\text { capacitance }(\mathrm{F} / \mathrm{m}) \\
& D=\text { spacing between conductor centers }(\mathrm{m}) \\
& \mathrm{a}=\text { conductor radius }(\mathrm{m}) \\
& \varepsilon_{1}=\text { relative dielectric constant }(1 \text { for air })
\end{aligned}
$$

The total capacitance between adjacent, isolated loop turns is given by

$$
\mathrm{C}^{\mathrm{i}}=\mathrm{C}^{\prime} \mathrm{P}
$$

where $P$ is the loop perimeter $(m)$. A similar method was used by Palermo [6]. The actual loop turns are connected as shown in Figure 2.

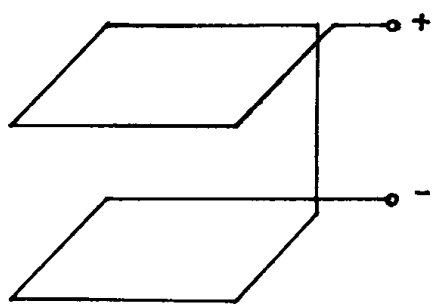

FIGURE 2. CAPACITANCE BETWEEN ADJACENT LOOP TURNS. 
The parallel transmission line is shorted at the end. The input capacitance of the shorted transmission line is given by

$$
\mathrm{C}_{\mathrm{T}}^{\mathrm{i}}=\int_{0}^{\mathrm{P}}\left(\frac{\mathrm{x}}{\mathrm{P}}\right)^{2} \mathrm{C}^{\prime} \mathrm{dx}=\frac{1}{3} \mathrm{C}^{\prime} \mathrm{P}
$$

Figure 3 shows the circuit model for a multi-turn loop where $\mathrm{L}_{\mathrm{L}}$ is the low frequency inductance of the loop and $\mathrm{C}^{\mathrm{i}} \mathrm{L}$ is the lumped internal capacitance actoss the loop terminals.

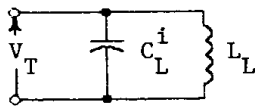

FIGURE 3. LOOP INTERNAL CAPACITANCE.

The total internal capacitive energy is

$$
E_{T}=\frac{1}{2} C_{L}^{i} V_{T}^{2}=\frac{1}{2} \sum_{j=2}^{\sum^{n}} C_{j}^{i} V_{j}^{2}
$$

where assuming a linear voltage drop

$$
\mathrm{V}_{\mathrm{j}}=\frac{2}{\mathrm{n}} \mathrm{V}_{\mathrm{T}}
$$

and $n$ is equal to the number of loop turns, then

$$
C_{L}^{i}=\sum_{j=2}^{n} \frac{C^{\prime} P}{3}\left(\frac{2}{n}\right)^{2}
$$

The lumped internal capacitance across the loop terminals is given by

$$
C_{L}^{i}=\frac{4}{3} \frac{(n-1)}{n^{2}} C^{\prime} P
$$

This equation is identical to the equation [7] for the capacitance between transformer winding layers with the exception of $\mathrm{C}$.

\section{External Loop Capacitance}

Capacitive coupling exists between the loop conductors and edge of pavement slot containing the conductors. Figure 4 illustrates the capacitive coupling. Since loop wires are typically closer to the top of the slot (i.e., sealant in bottom of slot supports conductors), the capacitive coupling between the conductors and bottom of the slot was neglected.

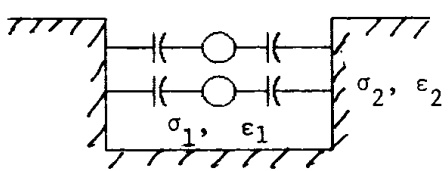

FIGURE 4. CAPACITANCE BETWEEN LOOP CONDUCTORS AND SLOT.
The external capacitance exists between a conductor and a material with variable dielectric constant and conductivity rather than metal Galejs [8] determines the impedance of a buried insulated wire. The capacitance is calculated assuming the region surrounding the slot or cavity is finitely conducting where region one is a low loss dielectric [9] or

$$
\left|j \omega e_{1}\right|>\sigma_{1}
$$

Stratton [10] also shows that a perfectly conducting outer conductor for a coaxial line provides a good approximation to a finitely conducting one when calculating shunt admittance. The slot walls are approximated by infinite conducting ground planes as illustrated in Figure 5

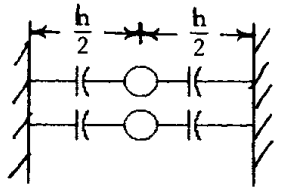

FIGURE 5. CAPACITANCE BETWEEN LOOP CONDUCTORS AND INFINITE CONDUCTING PLANES.

The characteristic impedance [11] of this conductor geometry is

$$
Z_{o}=\frac{138}{\sqrt{e_{s}}} \log _{10}\left(\frac{4 h}{d}\right)
$$

The capacitance per unit length of a TEM transmission line is

$$
C^{\prime}=\frac{120 \pi \varepsilon_{o} \sqrt{\varepsilon_{r}}}{Z_{o}}
$$

Then

$$
C^{\prime}=\frac{2 \pi \varepsilon_{\mathrm{o}} \varepsilon_{\mathrm{r}}}{\ln \left(\frac{4 \mathrm{~h}}{\mathrm{~d}}\right)}
$$

or

$$
C^{\prime}=\frac{1}{18} \frac{\varepsilon_{\mathrm{r}} \times 10^{-9}}{\ln \left(\frac{4 \mathrm{~h}}{\mathrm{~d}}\right)} \text { (Farads/meter) }
$$

The total external capacitance for the loop conductor is

$$
\mathrm{C}=\mathrm{C}^{\prime} \mathbf{P}
$$

Inductive loops are typically balanced as shown in Figure 6.

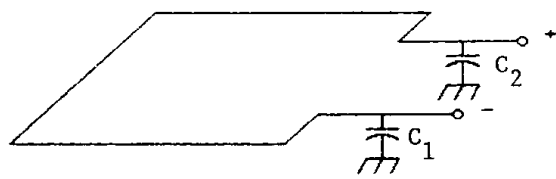

FIGURE 6. BALANCED INDUCTIVE LOOP.

Because of the balanced configuration and zero potential point at conductor perimeter center 


$$
C_{1}=C_{2}=\left(\frac{C^{\prime}}{3}\right)\left(\frac{P}{2}\right)=\frac{C^{\prime} P}{6}
$$

thus,

$$
C_{L}^{e}=C_{1} \| C_{2}=\frac{C^{\prime} P}{12}
$$

If one side of the loop is grounded

$$
C_{\mathrm{L}}^{\mathrm{e}}=\frac{\mathrm{C}^{\prime} \mathrm{P}}{3}
$$

\section{Loop Resistance Theory}

\section{Loop Resistance}

The series loop resistance, $R_{L}$, is comprised of the direct current wire resistance, $R$, the high frequency of skin effect resistance, Rac, and the ground resistance, Rg. The most important resistance is the ground resistance which is caused by currents induced in the conductive pavement and subgrade material. The ground resistance may limit loop sensitivity in locations with a large moisture content. The ground resistance is calculated by assuming the pavement and subgrade material causes a magnetic loss similar to that of a ferrite or iron core in an inductor. The permeability, $\mu \mathrm{g}$, of the pavement and subgrade material is assumed to be one. Appendix I presents a derivation of the ground resistance.

The series loop resistance is:

where

$$
\begin{aligned}
R_{L} & =R+R a c+R g \\
R g & =\tan \delta g \omega L_{L}
\end{aligned}
$$

$$
\begin{array}{ll}
\mathrm{R} L & =\text { series loop resistance }(\Omega) \\
\mathrm{R} & =\text { direct current loop resistance }(\Omega) \\
\mathrm{Rac} & =\text { skin effect resistance }(\Omega) \\
\mathrm{Rg} & =\text { ground resistance }(\Omega) \\
\mathrm{r} & =\text { loop wire radius }(\mathrm{m}) \\
\tan \delta \mathrm{g} & =\text { loss tangent of pavement material } \\
\mathrm{L} & =\text { loop self inductance }(\mathrm{Hy}) \\
\omega & =\text { operating frequency (radians) }
\end{array}
$$

Internal Inductance and Resistance Per Unit Cylindrical Conductor Length

Johnson [12] shows that the ratio of actual internal inductance to low-frequency internal inductance and internal resistance to lowfrequency internal resistance is given by:

$$
\frac{\mathrm{L}_{\mathrm{i}}}{\mathrm{L}_{\mathrm{io}}}=\frac{4}{\mathrm{q}}\left[\frac{\text { beiqbéiq }+ \text { berqbérq }}{(\text { béiq })^{2}+(\text { bérq })^{2}}\right]
$$

and

$$
\frac{R}{R_{0}}=\frac{q}{2}\left[\frac{\text { berqbeíq }- \text { beiqber' } q}{\left(\text { beíq }^{2}+\left(\text { ber' }^{\prime}\right)^{2}\right.}\right]
$$

where

$$
q=\frac{\rho(\sqrt{2})}{\delta}
$$

where

$$
d=\frac{1}{\sqrt{\mu_{\mathrm{r}} \mu_{\mathrm{o}} \pi \mathrm{f \sigma}}}
$$

$$
\begin{array}{ll}
\mathrm{Li} & =\text { internal inductance }(\mathrm{Hy} / \mathrm{m}) \\
\delta & =\text { skin depth }(\mathrm{m}) \\
\mu_{\mathrm{o}} & =\text { permeability of fre space }=4 \pi \times 10^{-7} \mathrm{Hy} / \mathrm{m} \\
\mu \mathrm{r} & =\text { relative permeability of copper wire }=1 \\
\mathrm{f} & =\text { frequency }(\mathrm{Hz}) \\
\sigma \quad= & \text { conductivity of copper wire }=0.58 \times 10^{8} \\
& \text { (mhos } / \mathrm{m}) \\
\rho & =\text { radius of wire }(\mathrm{m}) \\
\rho_{\mathrm{r}} & =\text { resistivity }(\text { ohm-meter })
\end{array}
$$

$$
\mathrm{L}_{\mathrm{io}}=\frac{\mu_{\mathrm{o}} \mu_{\mathrm{r}}}{8 \pi}(\mathrm{Hy} / \mathrm{m})
$$

$$
R_{0}=\frac{\rho_{\mathrm{r}}}{\pi \rho^{2}}
$$

$$
\rho_{\mathrm{r}}=1.74 \times 10^{-8} \text { ohm-meters for copper wire }
$$

Appendix II presents the formulas [13] for the complex Bessel Functions and their derivatives.

\section{Loop Inductance Theory}

\section{Self Inductance of Single Turn Circular Loop}

The self inductance [14] of a single turn circular loop is given by

$$
\mathrm{L}_{\mathrm{o}}=\mu_{\mathrm{r}} \mu_{\mathrm{o}}(2 \mathrm{r}-\mathrm{a})\left[\left(1-\frac{\mathrm{k}^{2}}{2}\right) \mathrm{K}(\mathrm{k})-\mathrm{E}(\mathrm{k})\right]
$$

where

$$
k^{2}=\frac{4 r(r-a)}{(2 r-a)^{2}}
$$

$$
\begin{aligned}
& \mathrm{L}_{\mathrm{O}}=\text { self inductance }(\mathrm{H}) \\
& \mathrm{E}(\mathrm{k})=\text { complete elliptic integral of first kind } \\
& \mathrm{K}(\mathrm{k})=\text { complete elliptic integral of second kind } \\
& \mathbf{r}=\text { radius of loop conductor center }(\mathrm{m}) \\
& \mathrm{a} \quad=\text { loop conductor radius }(\mathrm{m})
\end{aligned}
$$

The formula for $\mathrm{E}(\mathrm{k})$ [15] and $\mathrm{K}(\mathrm{k})$ [16] is given in Appendix III.

\section{Self Inductance of Multi-Turn Circular Loop}

The inductance formula for a circular coil with $\mathrm{N}$ equal spaced, identical turns following King [17] is given by:

$\mathrm{L}_{\mathrm{T}}=\mathrm{NLo}+2(\mathrm{~N}-1) \mathrm{M}_{12}+2(\mathrm{~N}-2) \mathrm{M}_{13}+\ldots .$.

or

$$
\mathrm{L}_{\mathrm{T}}=\mathrm{NL}_{\mathrm{o}}+2 \sum_{\mathrm{i}=1}^{\mathrm{n}}(\mathrm{n}-1) \mathrm{M}_{1,(\mathrm{i}+1)}
$$

where following Ramo [18]

$$
M=\mu_{r} \mu_{0} \sqrt{a b}\left[\left(\frac{2}{k}-k\right) K(k)-\frac{2}{k} E(k)\right]
$$




$$
k^{2}=\frac{4 a b}{d^{2}+(a+b)^{2}}
$$

with

$$
\begin{aligned}
& M=\text { mutual inductance }(\mathrm{H}) \\
& \mathrm{a}=\text { radius of turn one }(\mathrm{m}) \\
& \mathrm{b}=\text { radius of tum two }(\mathrm{m}) \\
& \mathrm{d}=\text { spacing between turns }(\mathrm{m})
\end{aligned}
$$

\section{External Inductance of Single Tum Rectangular Loop}

The external inductance of a single turn, rectangular loop is given by the sum of the inductance of two pairs of conductors. Then:

$$
\mathrm{L}_{\mathrm{o}}^{\mathrm{e}}=\mathrm{L}_{\mathrm{pl}}^{\mathrm{e}}+\mathrm{L}_{\mathrm{p} 2}^{\mathrm{e}}
$$

The external inductance of a single turn, rectangular loop is:

$$
\begin{gathered}
L_{0}^{e}=\frac{\mu_{0}}{\pi}\left\{1_{i} \ln \left[\frac{1_{1}}{\rho}+\sqrt{1+\left(\frac{1_{1}}{\rho}\right)_{2}}\right]\right. \\
-1_{i} \ln \left[\frac{1_{1}}{1_{2}}+\sqrt{1+\left(\frac{1_{1}}{1_{2}}\right)^{2}}\right] \\
+1_{2} \ln \left[\frac{1_{2}}{\rho}+\sqrt{1+\left(\frac{1_{2}}{\rho}\right)^{2}}\right] \\
-1_{2} \ln \left[\frac{1_{2}}{1_{1}}+\sqrt{1+\left(\frac{1_{2}}{1_{1}}\right)^{2}}\right] \\
-\sqrt{l_{1}^{2}+\rho^{2}}-\sqrt{1_{2}^{2}+\rho^{2}} \\
\left.+2 \sqrt{l_{1}^{2}+l_{2}^{2}}-\left(l_{1}+l_{2}\right)+2 \rho\right\}
\end{gathered}
$$

where

$$
\begin{aligned}
& 11=\text { width of loop }(\mathrm{m}) \\
& 12=\text { length of loop }(\mathrm{m})
\end{aligned}
$$

This equation can be written in more compact form by combining logarithms.

\section{Self Inductance of Single Tum Rectangular Loop}

The self inductance of a single turn rectangular loop is given by the sum of internal and external inductance and is:

$$
\mathrm{L}_{\mathrm{o}}=\mathrm{L}_{\mathrm{o}}^{\mathrm{i}}+\mathrm{L}_{\mathrm{o}}^{\mathrm{e}}
$$

where

$$
L_{0}^{i}=2\left(1_{1}+l_{2}\right) L^{i}
$$

and $\mathrm{L}^{\mathrm{i}}$ is given by equation (19) and $\mathrm{L}_{\mathrm{o}}$ is given by equation (32).

\section{Self Inductance of Multi-Turn Rectangular Loop}

The general inductance formula for a coil with $\mathrm{N}$ equal spaced, identical turns is:

$\mathrm{L}_{\mathrm{T}}=\mathrm{NLo}+2(\mathrm{~N}-1) \mathrm{M}_{12}+2(\mathrm{~N}-2) \mathrm{M}_{13}+\ldots \ldots$.

\section{Mutual Inductance of Two Coaxial. Parallel. Rectangular Loops}

The total mutual inductance of th rectangular loops in Figure 7 is given by the sum of the mutual inductances between the parallel sides and using formula (37) is

$$
\begin{aligned}
M= & 2\left[M_{13}\left(A, \sqrt{H^{2}+B^{2}}\right)-M_{11}(A, H)\right. \\
& \left.+M_{24}\left(B, \sqrt{H^{2}+B_{2}}\right)-M_{22}(B, H)\right]
\end{aligned}
$$

where $\mathrm{M}_{11}$ is the mutual inductance between side 1 of the bottom loop turn and side 1 of the top loop turn under consideration as shown. Note that all mutual inductances are symmetrical (i.e., $\mathrm{M}_{13},=\mathrm{M}_{31}$, etc)

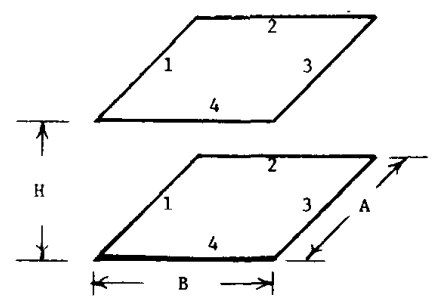

FIGURE 7. LOOP TURN GEOMETRY.

\section{Mutual Inductance of Parallel Filamentary Circuits}

The mutual inductance [19] between the pair of filamentary circuits located in free space and illustrated in Figure 8 is:

$$
M(1, d)=+\frac{\mu_{o} 1}{2 \pi}\left\{\begin{array}{c}
\ln \left[\frac{1}{d}+\sqrt{1+\left(\frac{1}{d}\right)^{2}}\right] \\
-1+\sqrt{\left(\frac{d}{1}\right)^{2}+\frac{d}{1}}
\end{array}\right\}
$$

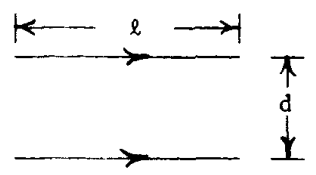

FIGURE 8. PAIR OF PARALLEL CURRENT ELEMENTS. 
where

$$
\begin{array}{ll}
\mu \mathrm{o} & =\text { permeability of free space }= \\
& 4 \pi \times 10^{-9} \mathrm{Hy} / \mathrm{m} \\
1 & =\text { filamentary length }(\mathrm{m}) \\
\mathrm{d} & =\text { filamentary spacing }(\mathrm{m}) \\
\mathrm{M}(1, \mathrm{~d}) & =\text { mutual inductance }(\mathrm{Hy})
\end{array}
$$

A plus sign is used when the direction of current in the filaments is the same and a minus sign is used when the direction of current in the filaments is opposite.

\section{Self Inductance of Multi-Turn Ouadrupole Loop}

Figure 9 presents an illustration [20] of a two turn quadrupole loop.

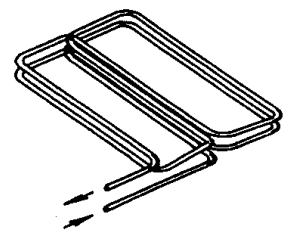

FIGURE 9. TWO TURN QUADRUPOLE LOOP.

The external inductance of an $\mathrm{N}$ turn quadrupole loop is:

$$
\begin{aligned}
\mathrm{LT}_{\mathrm{T}}= & 2 \mathrm{NL}_{\mathrm{O}}+2 \mathrm{NM}_{12}+4(\mathrm{~N}-1) \mathrm{M}_{13}+4(\mathrm{~N}-1) \mathrm{M}_{14}+ \\
& 4(\mathrm{~N}-2) \mathrm{M}_{15}+4(\mathrm{~N}-2) \mathrm{M}_{16}+\ldots . .
\end{aligned}
$$

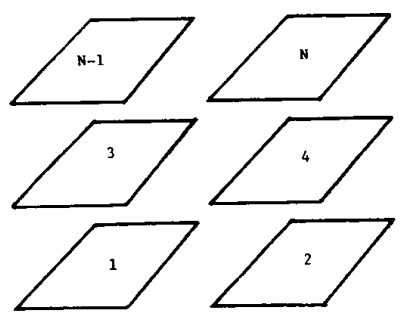

FIGURE 10. MULTI-TURN QUADRUPOLE LOOP.

\section{General Formula for Mutual Inductance of Parallel Filaments}

In order to calculate the mutual inductance between the offset loops in the quadrupole loop model, a general formula for the mutual inductance of parallel, offset filaments is required.

Following Jefimenko [21], the mutual inductance (Henry's) between the two parallel current filaments (meters) illustrated in Figure 11 is given by:

$$
M_{i k}= \pm \frac{\mu_{0} 1}{4 \pi}\left[\ln \left(\frac{(a+A)^{a}(b+B)^{b}}{(c+C)^{c}(d+D)^{d}}\right)+(D+C)-(B+A)\right]_{i k}
$$

where the positive sign is used for elements with currents in the same direction.

This formula, assumes that the elements lengths are much less than the wavelength divided by $2 \pi$ and the conductor radius is much less than the element length.

It should be noted that Grover [22] shows that this type of general formula can also be expressed by applying the laws of summation of mutual inductance to equation (37)

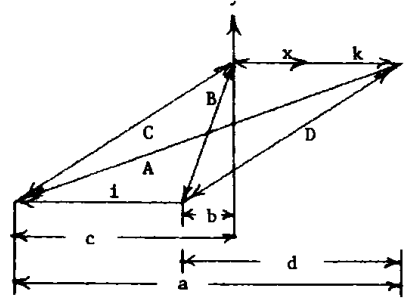

FIGURE 11. MUTUAL INDUCTANCE OF TWO PARALLEL SEGMENTS.

\section{Loop Circuit Model}

\section{Inductive Loop Circuit Model}

Figure 12 presents a circuit model of an inductive loop.

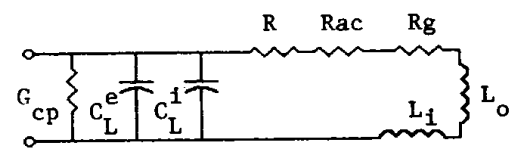

FIGURE 12. INDUCTIVE LOOP CIRCUIT MODEL.

Let

$$
\begin{aligned}
& \mathrm{Ls}=\mathrm{Lo}+\mathrm{Li} \\
& \mathrm{Rs}=\mathrm{R}+\mathrm{Rg} \\
& \mathrm{Cp}=\mathrm{C}_{\mathrm{L}}^{\mathrm{i}}+\mathrm{C}^{e_{\mathrm{L}}}
\end{aligned}
$$

Following Johnson [23], the slot dielectric loss conductance is

$$
\mathrm{G}=\tan \delta_{c} \omega C \mathrm{p}
$$

where $\tan \delta_{c}$ is the loss tangent of the slot sealer material.

Appendix IV shows the inductive loop circuit model of Figure 12 reduces to the circuit model of Figure 13 where

$$
R_{\text {in }}^{L}=\frac{G_{p}}{G_{p}^{2}+\left(\omega C_{p}-\frac{1}{\omega L}\right)_{p}^{2}}
$$

and

$$
x_{\text {in }}^{L}=\frac{\frac{1}{\omega L_{p}}-\omega C_{p}}{G_{p}^{2}+\left(\omega C_{p}-\frac{1}{\omega L_{p}}\right)^{2}}
$$

The loop quality factor is given by

$$
Q_{i n}^{L}=\frac{X_{i n}^{L}}{R_{i n}^{L}}=\frac{\frac{1}{\omega L_{p}}-\omega C_{p}}{G_{p}}
$$

The self resonant frequency of the loop is given by

$$
\text { fo }=\frac{1}{2 \pi} \sqrt{\mathrm{L}_{\mathrm{p}} \mathrm{C}_{\mathrm{p}}}
$$




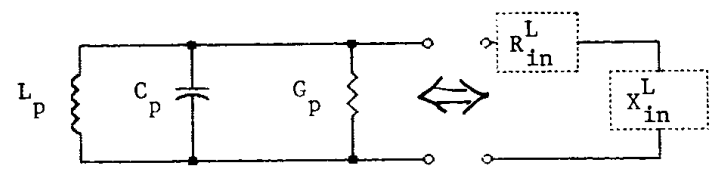

FIGURE 13. EQUTVALENT LOOP CIRCUIT MODEL.

\section{Loop Transmission Line Theory}

\section{Loop Transmission Line Model}

A transmission line connects the roadway loop with roadside detector electronics. The complex impedance $\left(Z_{L}\right)$ of the loop is transformed to a complex impedance, $\mathrm{Z}_{\mathrm{in}}$, by the transmission line cable by the following equation [24].

$$
Z_{\text {in }}^{c}=Z_{o} \frac{Z_{L}+Z_{o} \tanh \gamma 1}{Z_{0}+Z_{L} \tanh \gamma 1}
$$

where

$$
\begin{aligned}
& Z_{L}=R_{L}+j \omega L_{L} \\
& Z_{o}=\sqrt{\frac{R+j \omega L}{G+j \omega C}} \\
& \gamma=\sqrt{(R+j \omega L)(G+j \omega C)}
\end{aligned}
$$

with

$$
\begin{aligned}
R & =\text { transmission line per unit resistance } \\
(\Omega / \mathrm{m}) & \\
\mathrm{G} & =\text { transmission line per unit conductance } \\
& (\Omega / \mathrm{m}) \\
\mathrm{L} & =\text { transmission line per unit inductance } \\
& (\mathrm{H} / \mathrm{m}) \\
\mathrm{C} & =\text { transmission line per unit capacitance } \\
& (\mathrm{F} / \mathrm{m}) \\
\mathrm{R}_{\mathrm{L}} & =\text { loop equivalent resistance }(\Omega) \\
\mathrm{L}_{\mathrm{L}} & =\text { loop equivalent inductance }(\mathrm{H}) \\
\omega & =\text { radian frequency }
\end{aligned}
$$

A useful equation [25] for computing Zin is given by

$$
\tanh (x \pm j y)=\frac{\sinh 2 x \pm j \sin 2 y}{\cosh 2 x+\cos 2 y}
$$

\section{Frequency Shift Detector System Sensitivity}

The frequency shift, $\Delta \mathrm{fD}_{\mathrm{D}}$, at the detector terminals is required as a function of loop and cable parameters.

$$
\text { Let } \begin{aligned}
\text { Let } & \mathrm{f}_{\mathrm{V}}-\mathrm{f}_{\mathrm{NV}} & =-\Delta \mathrm{f}_{\mathrm{D}} \\
\text { and } & \mathrm{f}_{\mathrm{NV}} & =\mathrm{f}_{\mathrm{D}}
\end{aligned}
$$

Then

$$
\frac{\Delta f_{D}}{f_{D}}=-\frac{1}{2} S_{D}
$$

Since $\quad L_{D}=L_{L}+L_{C}$

and $\quad \Delta \mathrm{L}_{\mathrm{D}}=\Delta \mathrm{L}_{\mathrm{L}}$

$$
\frac{\Delta f_{D}}{f_{D}}=-\frac{1}{2} S_{L}\left(\frac{1}{1+\frac{L_{c}}{L_{L}}}\right)
$$

where

$$
\mathrm{S}_{\mathrm{L}}=\frac{\Delta \mathrm{L}}{\mathrm{L}}
$$

This equation shows that the cable inductance, $\mathrm{L}_{C}$, is important relative to frequency shift detection sensitivity. If the cable inductance is one tenth or less of the loop inductance, the transmission line has a negligible effect on Inductance Loop Detector (ILD) sensitivity provided the quality factor, $\mathrm{QD}$, is five or greater. The frequency shift detector system sensitivity results also apply to period shift detector systems.

\section{Loop Transformer Theory}

\section{Inductive Loop Transformer Model}

A transformer [26] with low leakage inductance (i.e., total series leakage inductance less than transmission line inductance) can be placed between the loop and transmission line to transform the loop inductance to a value larger than the transmission line inductance. The transformer will remove the reduction in sensitivity caused by the transmission line.

The transformer model [27] used is shown in Figure 14.

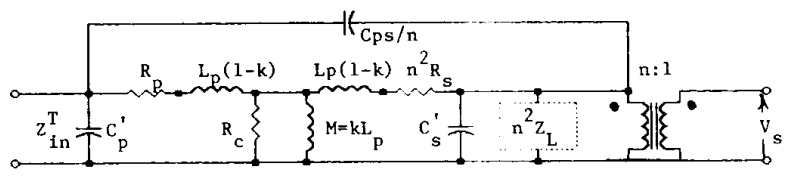

FIGURE 14. LOOP TRANSFORMER MODEL.

where all parameters are referred to the primary

$$
\begin{array}{ll}
\mathrm{R}_{\mathrm{p}} & =\text { primary winding resistance } \\
\mathrm{Rc} & =\text { resistance corresponding to core loss } \\
\mathrm{n}^{2} \mathrm{R}_{\mathrm{S}} & =\text { referred secondary winding resistance } \\
\mathrm{n}^{2} \mathrm{Z}_{\mathrm{L}} & =\text { referred load impedance } \\
\mathrm{Cp} & =\text { primary capacitance } \\
\mathrm{Cs} & =\text { secondary capacitance } \\
\mathrm{Cs}^{\prime} & =\text { modified secondary shunting capacitance } \\
\qquad \mathrm{Cs}^{\prime}=\frac{\mathrm{Cs}}{\mathrm{n}^{2}}+\frac{\mathrm{Cps}}{\mathrm{n}}\left(\frac{1}{\mathrm{n}}-1\right)
\end{array}
$$

$\mathrm{Cps} / \mathrm{n}=$ referred primary to secondary capacitance

$\mathrm{Cp}^{\prime} \quad=$ modified primary capacitance

$$
\mathrm{Cp}^{*}=\mathrm{Cp}+\mathrm{Cps}\left(1-\frac{1}{\mathrm{n}}\right)
$$

$\mathrm{n} \quad=$ ratio of primary to secondary turn

$$
\mathrm{n}=\frac{\sqrt{\mathrm{L}_{\mathrm{p}}}}{\sqrt{\mathrm{L}_{\mathrm{S}}}}
$$

$\mathrm{Lp} \quad=$ open circuit primary inductance at low frequency

$\mathrm{Lp}(1-\mathrm{k})=$ one-half total leakage inductance

$\mathrm{K}$ = coupling coefficient

$$
K=\frac{\text { mutual inductance }}{\sqrt{\mathrm{L}_{\mathrm{P}} \mathrm{L}_{\mathrm{S}}}}=\frac{\mathbf{M}}{\sqrt{\mathrm{L}_{\mathrm{p}} \mathrm{L}_{\mathrm{S}}}}
$$

The equivalent transformer model of Figure 15 was used to determine the transformed load impedance 


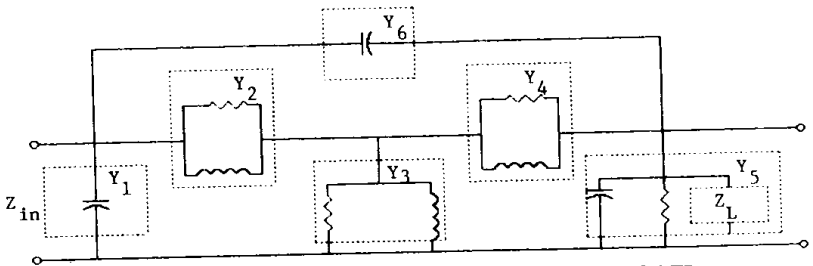

FIGURE 15. EQUIVALENT TRANSFORMER MODEL.
The comparison of measured and calculated results is seen to be favorable. Measured loop inductance and quality factor data versus frequency was unavailable for quadrupole and circular loops.

In Appendix V it is shown that

$$
Z_{\text {in }}^{T}=\frac{\left(Y_{2}+Y_{3}+Y_{4}\right)\left(Y_{4}+Y_{5}+Y_{6}\right)-Y_{4}^{2}}{\left(Y_{1}+Y_{2}+Y_{3}\right)\left[\left(Y_{2}+Y_{3}+Y_{4}\right)\left(Y_{4}+Y_{5}+Y_{6}\right)-Y_{4}^{2}\right]-2 Y_{2} Y_{4} Y_{6}-Y_{6}^{2}\left(Y_{2}+Y_{3}+Y_{4}\right)-Y_{2}^{2}\left(Y_{4}+Y_{5}+Y_{6}\right)}
$$

\section{Loop Computer Program}

\section{Loop Detector Analysis System (LDAS) Program}

The LDAS computer program calculates loop inductance and quality factor for rectangular, quadrupole, and circular loops. The loop inductance and quality factor is transformed by the transmission line, (non-shielded twisted loop wire) to roadside junction box and transmission line (shielded twisted pair) between junction box and detector electronics in controller box. The program also allows a transformer between the loop and transmission line or between the two types of transmission lines.

The LDAS program is menu driven and written in Microsoft Quick Basic. All mathematical functions are computed using double precision calculations.

\section{Measured Data and Calculated Results}

\section{Comparison of Calculated and Measured Loop Self Inductance} and Ouality Factor

Table I presents measured self inductance and quality factor data for a $1.83 \mathrm{~m}(6 \mathrm{ft})$ by $1.83 \mathrm{~m}(6 \mathrm{ft})$ three turn inductance loop. A comparison between measured and LDAS computed data is presented in Table II.

\section{$\underline{\text { Results and Conclusions }}$}

Tables III through V present calculated loop inductance and quality factor as a function of conductor size. The quality factor decreases with increasing wire gauge as expected. The addition of a transmission line of 240 feet length approximately halves the quality factor. Detector applications requiring transmission lines over 200 feet in length should use number 12 AWG wire for the loop and non-shielded transmission line. Three to four turns of loop wire have an adequate quality factor. One to two turn loops should be used with a transformer.

Loop inductance should be measured at $1 \mathrm{kHz}$ to remove effects of capacitance when determining the number of turns of a buried loop. All loop measurements at frequencies of $20 \mathrm{kHz}$ or greater should be made with a balanced instrument since the loop detector electronics is balanced. An unbalanced measurement will result in wrong values because of the different capacitance to ground. Since the external capacitance is determined by the dielectric constant of the slot sealing material, the loop conductors should be completely sealed to prevent water in the loop slot. The high dielectric constant of water will cause a significant change in the external capacitance causing the apparent loop inductance to change. Unstable loop detector operations results from incomplete sealing of the loop slot.

Table I. Measured inductive loop parameters with vehicle not present

\begin{tabular}{|c|c|c|c|c|c|c|}
\hline$f_{o}$ & $f_{2}$ & $f_{1}$ & $Q=\frac{f_{o}}{f_{2}-f_{1}}$ & C & $L=\frac{1}{(2 \pi f)^{2}}$ & $R=\frac{2 \pi f_{o} L}{Q}$ \\
\hline$(\mathrm{KHz})$ & 3db(KHz) & $3 \mathrm{db}(\mathrm{KHz})$ & & $(\mathrm{mF})$ & $(\mu \mathrm{H})$ & $(\Omega)$ \\
\hline $\begin{array}{l}20 \\
25 \\
30 \\
35 \\
40 \\
45 \\
50 \\
55 \\
50\end{array}$ & $\begin{array}{l}20.334 \\
25.372 \\
30.388 \\
35.427 \\
40.470 \\
45.514 \\
50.571 \\
55.633 \\
60.704\end{array}$ & $\begin{array}{l}19.702 \\
24.688 \\
29.644 \\
34.607 \\
39.573 \\
49.472 \\
49.472 \\
54.407 \\
59.342\end{array}$ & $\begin{array}{l}31.7 \\
35.5 \\
40.3 \\
42.7 \\
44.6 \\
45.7 \\
45.5 \\
44.9 \\
44.1\end{array}$ & $\begin{array}{l}0.856490 \\
0.548109 \\
0.380000 \\
0.278693 \\
0.212056 \\
0.167887 \\
0.135704 \\
0.111845 \\
0.093450\end{array}$ & $\begin{array}{l}73.9 \\
73.9 \\
74.1 \\
74.2 \\
74.3 \\
74.5 \\
74.7 \\
74.9 \\
75.3\end{array}$ & $\begin{array}{l}0.29 \\
0.33 \\
0.35 \\
0.38 \\
0.42 \\
0.46 \\
0.52 \\
0.58 \\
0.64\end{array}$ \\
\hline
\end{tabular}

Comments:

Loop Size: $1.83 \mathrm{~m}(6 \mathrm{ft})$ by $1.83 \mathrm{~m}(6 \mathrm{ft})$

Loop Number of Turns: 3

Loop Wire Size: 14 Gauge

Loop Lead in Length: $1.52 \mathrm{~m}$ (60in)

Loop Self-Resonant Frequency: $697.06 \mathrm{kHz}$

Note: $50 \mathrm{pf}$ residual capacitance in decade box neglected in $\mathrm{C}$ value. 
Table II. Comparison of Calculated and Measured Loop Parameters.

\begin{tabular}{ccccc}
\hline $\begin{array}{c}\mathrm{F}_{\mathrm{O}} \\
(\mathrm{KHz})\end{array}$ & $\begin{array}{c}\text { Measured L } \\
(\mu \mathrm{H})\end{array}$ & $\begin{array}{c}\text { Calculated L } \\
(\mu \mathrm{H})\end{array}$ & Measured Q & Calculated Q \\
\hline 20 & 73.9 & 74.4 & 31.7 & \\
\hline 25 & 73.9 & 74.4 & 35.5 & 30.4 \\
30 & 74.1 & 74.3 & 40.3 & 33.9 \\
35 & 74.2 & 74.3 & 42.7 & 38.8 \\
40 & 74.3 & 74.3 & 44.6 & 40.6 \\
45 & 74.5 & 74.3 & 45.7 & 43.7 \\
50 & 74.7 & 74.3 & 44.9 & 44.9 \\
55 & 74.9 & 74.3 & 44.1 & 46.1 \\
60 & 75.3 & & & \\
\hline
\end{tabular}

Calculated Loop Parameters:

- pavement loop slot width (mils): 375

- loop slot sealant dielectric constant: 6

- pavement material loss tangent: .01

- loop wire insulation dielectric constant: 2.5

- effective loop wire insulation loss tangent: .001

- loop conductor spacing (mils): 200

- American wire Gauge, AWG: 14

Table III. Rectangular Loop Parameters

\begin{tabular}{|c|c|c|c|c|c|c|c|c|c|c|}
\hline \multirow[b]{2}{*}{$\begin{array}{c}\text { Wire } \\
\text { Gauge } \\
\text { (AWG) }\end{array}$} & \multicolumn{2}{|c|}{1 Turn } & \multicolumn{2}{|c|}{2 Turn } & \multicolumn{2}{|c|}{3 Turn } & \multicolumn{2}{|c|}{4 Turn } & \multicolumn{2}{|c|}{5 Turn } \\
\hline & $\begin{array}{c}\text { Inductance } \\
(\mu \mathrm{H})\end{array}$ & $\begin{array}{l}\text { Quality } \\
\text { Factor }\end{array}$ & $\begin{array}{c}\text { Inductance } \\
(\mu \mathrm{H})\end{array}$ & $\begin{array}{l}\text { Quality } \\
\text { Factor }\end{array}$ & $\begin{array}{c}\text { Inductance } \\
(\mu \mathrm{H})\end{array}$ & $\begin{array}{l}\text { Quality } \\
\text { Factor }\end{array}$ & $\begin{array}{l}\text { Inductance } \\
(\mu \mathrm{H})\end{array}$ & $\begin{array}{c}\text { Quality } \\
\text { Factor }\end{array}$ & $\begin{array}{c}\text { Inductance } \\
(\mu \mathrm{H})\end{array}$ & $\begin{array}{l}\text { Quality } \\
\text { Factor }\end{array}$ \\
\hline 12 & 10.13 & 19.68 & 35.22 & 29.88 & 73.28 & 37.13 & 123.14 & 42.65 & 184.00 & 47.03 \\
\hline 14 & 10.50 & 15.61 & 35.96 & 24.06 & 74.39 & 30.40 & 124.62 & 35.41 & 185.85 & 39.51 \\
\hline $14^{*}$ & 63.45 & 11.59 & 89.16 & 14.11 & 128.18 & 17.51 & 179.61 & 21.20 & 242.96 & 24.86 \\
\hline $14^{* *}$ & 351.70 & 1.77 & 853.20 & 4.90 & 1433.69 & 9.99 & 1985.51 & 17.24 & 2464.16 & 26.76 \\
\hline 16 & 10.85 & 11.57 & 36.68 & 18.10 & 75.46 & 23.25 & 126.04 & 27.50 & 187.62 & 31.09 \\
\hline 18 & 11.20 & 8.11 & 37.37 & 12.84 & 76.50 & 16.73 & 127.42 & 20.05 & 189.34 & 22.95 \\
\hline
\end{tabular}

*Transmission Line

**Transformer Loop

Note: $1.20 \mathrm{kHz}$, other parameters given for Table II

2. All inductance and quality factors in Table III are apparent values (i.e., the effect of loop capacitance and resistance is included)

3. Transformer Parameters

Primary Resistance (OHMS)

Primary Capacitance (PICOFARADS)

Primary Inductance (MILLIHENRY'S)

Secondary Resistance (OHMS)

Secondary Capacitance (PICOFARADS)

Primary to Secondary Turns Ratio

Core Loss Resistance (OHMS)

Coupling Coefficient

Primary to Secondary Capacitance (PF)

4. Transmission Line Parameters:

- length (ft):

- resistance (milliohms/ft):

- inductance (microhenry's/ft):

- conductance (micromhos/fit):

- capacitance (picofarads/ft)

$$
\begin{aligned}
& =1 \\
& =10 \\
& =5 \\
& =1 \\
& =10 \\
& =5 \\
& =1000000 \\
& =.99 \\
& =10 \\
& 240 \\
& 2.5 \\
& 0.22 \\
& 0.000076
\end{aligned}
$$$$
26
$$ 
Table IV. Quadrupole Loop Parameters

\begin{tabular}{|c|c|c|c|c|c|c|c|c|c|c|}
\hline & \multicolumn{2}{|c|}{1 Turn } & \multicolumn{2}{|c|}{2 Turn } & \multicolumn{2}{|c|}{3 Tum } & \multicolumn{2}{|c|}{$4 \mathrm{Tum}$} & \multicolumn{2}{|c|}{5 Tum } \\
\hline $\begin{array}{l}\text { Wire } \\
\text { Gauge } \\
\text { (AWG) }\end{array}$ & $\begin{array}{l}\text { Inductance } \\
\qquad(\mu \mathrm{H})\end{array}$ & $\begin{array}{c}\text { Quality } \\
\text { Factor }\end{array}$ & $\begin{array}{l}\text { Inductance } \\
\qquad(\mu \mathrm{H})\end{array}$ & $\begin{array}{l}\text { Quality } \\
\text { Factor }\end{array}$ & $\begin{array}{l}\text { Inductance } \\
\qquad(\mu \mathrm{H})\end{array}$ & $\begin{array}{l}\text { Quality } \\
\text { Factor }\end{array}$ & $\begin{array}{c}\text { Inductance } \\
(\mu \mathrm{H})\end{array}$ & $\begin{array}{l}\text { Quality } \\
\text { Factor }\end{array}$ & $\begin{array}{l}\text { Inductance } \\
(\mu \mathrm{H})\end{array}$ & $\begin{array}{l}\text { Quality } \\
\text { Factor }\end{array}$ \\
\hline 12 & 17.14 & 21.72 & 60.15 & 32.74 & 125.42 & 40.32 & 210.78 & 45.93 & 314.77 & 50.27 \\
\hline 14 & 17.69 & 17.26 & 61.26 & 26.53 & 127.08 & 33.28 & 212.98 & 38.48 & 317.49 & 42.64 \\
\hline 16 & 18.22 & 12.81 & 62.32 & 20.07 & 128.67 & 25.67 & 215.09 & 30.18 & 320.10 & 33.91 \\
\hline 18 & 18.74 & 8.99 & 63.36 & 14.32 & 130.22 & 18.61 & 217.15 & 22.21 & 322.65 & 25.29 \\
\hline
\end{tabular}

Note: $1.20 \mathrm{kHz}$, lateral conductor spacing, 200 mils, other parameters given for Table II

2. All inductance and quality factors in Table III are apparent values (i.e., the effect of loop capacitance and resistance is included)

Table V. Circular Loop Parameters

\begin{tabular}{|c|c|c|c|c|c|c|c|c|c|c|}
\hline \multirow[b]{2}{*}{$\begin{array}{c}\text { Wire } \\
\text { Gauge } \\
\text { (AWG) }\end{array}$} & \multicolumn{2}{|c|}{1 Turn } & \multicolumn{2}{|c|}{2 Turn } & \multicolumn{2}{|c|}{3 Turn } & \multicolumn{2}{|c|}{4 Turn } & \multicolumn{2}{|c|}{5 Turn } \\
\hline & $\begin{array}{c}\text { Induxtance } \\
\qquad(\mu \mathrm{H})\end{array}$ & $\begin{array}{l}\text { Quality } \\
\text { Factor }\end{array}$ & $\begin{array}{l}\text { Inductance } \\
\qquad(\mu \mathrm{H})\end{array}$ & $\begin{array}{l}\text { Quality } \\
\text { Factor }\end{array}$ & $\begin{array}{c}\text { Inductance } \\
\qquad(\mu \mathrm{H})\end{array}$ & $\begin{array}{l}\text { Quality } \\
\text { Factor }\end{array}$ & $\begin{array}{l}\text { Inductance } \\
\qquad\left(\mu_{H}\right)\end{array}$ & $\begin{array}{l}\text { Quality } \\
\text { Factor }\end{array}$ & $\begin{array}{l}\text { Inductance } \\
(\mu \mathrm{H})\end{array}$ & $\begin{array}{l}\text { Quality } \\
\text { Factor }\end{array}$ \\
\hline 12 & 9.70 & 20.39 & 33.95 & 30.95 & 70.91 & 38.42 & 119.50 & 44.07 & 179.00 & 48.53 \\
\hline 14 & 10.04 & 16.19 & 34.63 & 24.98 & 71.93 & 31.55 & 120.86 & 36.73 & 180.69 & 40.95 \\
\hline 16 & 10.37 & 12.00 & 35.29 & 18.83 & 72.91 & 24.21 & 122.16 & 28.63 & 182.31 & 32.36 \\
\hline 18 & 10.68 & 8.42 & 35.92 & 13.38 & 73.86 & 17.47 & 123.43 & 20.96 & 183.89 & 24.00 \\
\hline
\end{tabular}

Note: $1.20 \mathrm{kHz}$, Loop diameter: $7 \mathrm{feet}$, other parameters given for Table II

2. All inductance and quality factors in Table III are apparent values (i.e., the effect of loop capacitance and resistance is included)

Appendix I

\section{Loop Ground Resistance Derivation}

The complex impedance, $Z_{L}$, of the loop results from a complex permeability, $\mu \mathrm{g}$, and is:

$$
\begin{aligned}
Z & =j \omega \mu g L_{L} \\
& =j \omega\left(\mu g^{\prime}-j \mu g^{\prime \prime}\right) L_{L}
\end{aligned}
$$

The material loss tangent, $\tan \delta \mathrm{g}$, is:

$$
\tan \delta \mathrm{g}=\frac{\mu " \mathrm{~g}}{\mu \mathrm{g}}
$$

Letting $\mu g^{\prime}=1$

the loss tangent is

Then

$$
\tan \delta g=\mu g^{\prime \prime}
$$

$$
\begin{aligned}
& \mathrm{Z}_{\mathrm{L}}=j \omega(1-j \tan \delta g) \mathrm{L}_{\mathrm{L}} \\
& \mathrm{Z}_{\mathrm{L}}=\omega \tan \delta g \mathrm{~L}_{\mathrm{L}}+j \omega \mathrm{L}_{\mathrm{L}} \\
& \mathrm{Z}_{\mathrm{L}}=\mathrm{Rg}+\mathrm{j} \mathrm{X}_{\mathrm{L}} \\
& \mathrm{Rg}=\tan \delta g \omega \mathrm{L}_{\mathrm{L}}
\end{aligned}
$$

\section{Appendix II}

Real Part of complex Bessel Function of First Kind

$$
\begin{aligned}
& \text { ber } x=1-\frac{\left(\frac{1}{2} x\right)^{4}}{(2 !)^{2}}+\frac{\left(\frac{1}{2} x\right)^{8}}{(4 !)^{2}}-\ldots \ldots . . \\
& \text { ber } x=1+\sum_{n=1}^{\infty}(-1)^{n} \frac{\left(\frac{1}{2} x\right)^{4 n}}{(2 n !)^{2}}
\end{aligned}
$$

Derivative of Real Part

$$
\begin{aligned}
& \text { ber ' } x=-\frac{\left(\frac{1}{2} x\right)^{3}}{1 ! 2 !}+\frac{\left(\frac{1}{2} x\right)^{7}}{3 ! 4 !}-\frac{\left(\frac{1}{2} x\right)^{11}}{5 ! 6 !}+\ldots \ldots \\
& \text { ber' } x=\sum_{n=1}^{\infty}(-1)^{n} \frac{\left(\frac{1}{2} x\right)^{(4 n-1)}}{(2 n-1) ! 2 n !}
\end{aligned}
$$

Imaginary Part of complex Bessel Function of First Kind 


$$
\begin{aligned}
& \text { bei } x=\frac{\left(\frac{1}{2} x\right)^{2}}{(1 !)^{2}}-\frac{\left(\frac{1}{2} x\right)^{6}}{(3 !)^{2}}+\frac{\left(\frac{1}{2} x\right)^{10}}{(5 !)^{2}}-\ldots . . \\
& \text { bei } x=\sum_{n=1}^{\infty}-(-1)^{n} \frac{\left(\frac{1}{2} x\right)^{(4 n-2)}}{[(2 n-1) !]^{2}}
\end{aligned}
$$

Derivative of Imaginary Part

$$
\begin{aligned}
& \text { bei' } x=\frac{1}{2} x-\frac{\left(\frac{1}{2} x\right)^{5}}{2 ! 3 !}+\frac{\left(\frac{1}{2} x\right)^{9}}{4 ! 5 !}-\ldots . . \\
& \text { bei'x }=\sum_{n=1}^{\infty}-(-1)^{n} \frac{\left(\frac{1}{2} x\right)^{(4 n-3)}(\text { II }-4)}{(2 n-2) !(2 n-1) !} \\
& \text { Appendix III }
\end{aligned}
$$

Complete Elliptic Integral of First kind

$$
\begin{array}{ll}
\mathrm{K}(\mathrm{k})=\frac{\pi}{2} \prod_{\mathrm{m}=\mathbf{0}}^{\infty}\left(1+\mathbf{k}_{\mathrm{m}+1}\right) & (\text { III-1) } \\
\mathbf{k}_{\mathrm{m}+1}=\left(1-\mathbf{k}_{\mathrm{m}}\right) /\left(1+\mathbf{k}_{\mathrm{m}}\right) & (\text { III-2) } \\
\mathbf{k}_{\mathrm{m}^{\prime}}=\sqrt{1-\mathbf{k}_{\mathrm{m}}^{2}} \\
\mathbf{k}_{\mathrm{o}} \equiv \mathbf{k}
\end{array}
$$

Complete Elliptic Integral of Second Kind

$$
\begin{aligned}
& E(u)=\frac{\pi}{2(1-u)}\left[1+\frac{u^{2}}{2^{2}}+\frac{1^{2}}{2^{2} \cdot 4^{2}} u^{4}+\frac{1^{2} \cdot 3^{2}}{2^{2} \cdot 4^{2} \cdot 6^{2}} u^{6}+\ldots . .\right] \\
& E(u)=\frac{\pi}{2(1-u)}\left[1+\sum_{N=1}^{\infty}\left[\frac{(2 N-3) ! !}{2 N ! !}\right]^{2} u^{2 N}\right] \quad(\text { III-5) } \\
& u=\left(1-k^{\prime}\right) /\left(1 / k^{\prime}\right) \\
& k^{\prime}=\sqrt{1-m} \\
& M=k^{2} \\
& \text { Note: } 2 N ! ! \equiv 2^{n N} !
\end{aligned}
$$

\section{FIGURE IV-2. LOOP SERIES/PARALLEL CIRCUIT EQUIVALENCY.}

From Figure IV-2

$$
\begin{aligned}
& \mathrm{Gp}=\mathrm{GLp}+\mathrm{Gcp} \\
& \mathrm{Y}_{\text {in }}^{\mathrm{L}}=\mathrm{Gp}+\mathrm{j}\left(\omega \mathrm{Cp}-\frac{1}{\omega L \mathrm{Lp}}\right) \\
& \mathrm{Z}_{\text {in }}^{\mathrm{L}}=\frac{1}{\mathrm{Y}_{\text {in }}}
\end{aligned}
$$




\section{Appendix $Y$}

Transformer Model Input impedance

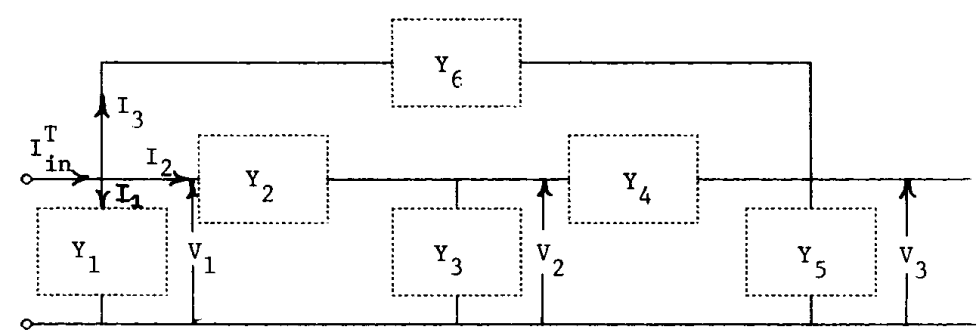

$$
\begin{gathered}
{\left[\begin{array}{l}
1 \\
0 \\
0
\end{array}\right]=\left[\begin{array}{ccc}
Y_{1}+Y_{2}+Y_{6} & -Y_{2} & -Y_{6} \\
-Y_{2} & Y_{2}+Y_{3}+Y_{4} & -Y_{4} \\
-Y_{6} & -Y_{4} & Y_{4}+Y_{5}+Y_{6}
\end{array}\right]\left[\begin{array}{l}
V_{1} \\
V_{2} \\
V_{3}
\end{array}\right]} \\
I_{\text {in }}^{T}=I_{1}+I_{2}+I_{3} \\
I_{\text {in }}^{T}=Y_{1} V_{1}+Y_{6}\left(V_{1}-V_{3}\right)+Y_{2}\left(V_{1}-V_{2}\right) \\
Z_{\text {in }}^{T}=\frac{V_{1}}{\operatorname{lin}}=\frac{(V-3)}{Y_{1}+Y_{6}\left(1-\frac{V_{3}}{V_{1}}\right)+Y_{2}\left(1-\frac{V_{2}}{V_{1}}\right)}
\end{gathered}
$$

$$
\left[\begin{array}{l}
V_{1} \\
V_{2} \\
V_{3}
\end{array}\right]=\left[\begin{array}{ccc}
Y_{11} & Y_{12} & Y_{13} \\
Y_{21} & Y_{22} & Y_{23} \\
Y_{31} & Y_{32} & Y_{33}
\end{array}\right]^{-1}\left[\begin{array}{l}
1 \\
0 \\
0
\end{array}\right]=\left[\begin{array}{lll}
Y_{11}^{\prime} & Y_{12}^{\prime} & Y_{13} \\
Y_{21}^{\prime} & Y_{22}^{\prime} & Y_{23}^{\prime} \\
Y_{31}^{\prime} & Y_{32}^{\prime} & Y_{33}^{\prime}
\end{array}\right]=\left[\begin{array}{l}
1 \\
0 \\
0
\end{array}\right]
$$

$$
\begin{aligned}
& \mathrm{V}_{1}=\mathrm{Y}_{11}^{\prime}=\frac{\mathrm{V}_{22} \mathrm{Y}_{33}-\mathrm{Y}_{23} \mathrm{Y}_{32}}{|\mathrm{Y}|} \\
& \mathrm{V}_{2}=\mathrm{Y}_{21}^{\prime}=\frac{-\left(\mathrm{Y}_{21} \mathrm{Y}_{33}-\mathrm{Y}_{23} \mathrm{Y}_{31}\right.}{|\mathrm{Y}|} \\
& \mathrm{V}_{3}=\mathrm{Y}_{31}{ }^{\prime}=\frac{\mathrm{Y}_{21} \mathrm{Y}_{32}-\mathrm{Y}_{22} \mathrm{Y}_{31}}{|\mathrm{Y}|}
\end{aligned}
$$

where

$$
\begin{aligned}
& Y_{21}=-Y_{2} \\
& Y_{22}=Y_{2}+Y_{3}+Y_{4} \\
& Y_{23}=-Y_{4} \\
& Y_{31}=-Y_{6} \\
& Y_{32}=-Y_{4} \\
& Y_{33}=Y_{4}+Y_{5}+Y_{6}
\end{aligned}
$$




\section{Acknowledgements}

The author expresses thanks to Mr. Lyle Saxton, and Mr. Frank Mammano of the Federal Highway Administration (FHWA), whose support made this work possible. Thanks are also due to Mr. Richard Lavigne of FHWA for helpful discussions, and review of the work, and to Holly Dellinger of FHWA for typing the manuscript. Finally, thanks are due to Mr. Ammar Kanaan of SRA Technologies of Alexandria, Virginia, for the excellent software development.

\section{References}

[1]. Mills, M. K., "Self Inductance Formulas for Multi-Turn Rectangular Loops Used with Vehicle Detectors," 33rd IEEE VTG Conference Record, pp. 64-73, May 1983.

[2]. Mills, M. K., "Self Inductance Formulas for Quadrupole Loops Used with Vehicle Detectors," 35th IEEE VTG Conference Record, pp. 81-87, May 1985.

[3]. King, R. W. P., Fundamental Electro-Magentic Theory, Dover Publishing, Inc., pp. 450-456, 1962.

[4]. Langford-Smith, F., Radiotron Designer's Handbook, Wineless Press, pp. 219-221, 1953.

[5]. Johnson, W. C., Transmission Lines and Networks, McGraw Hill Book Company, Inc. p. 85, 1950

[6]. Palermo, A. J., "Distributed Capacity of Single-Layer Coils", Proc. I.R.E., 22.7, p. 897, July 1934.

[7]. Langford-Smith, F., op. cit., p. 221.

[8]. Galejs, Janis, Antennas in Inhomogeneous Media, Pergamon Press, pp. 60-64, 1969

[9]. Ramo, S., Whinnery, J.R., and Van Duzer, J., Fields and Waves in Communication Electronics, John Wiley and Sons, Inc., p. 336, 1965.

[10]. Stratton, J. A., Electromagnetic Theory, McGraw Hill Book Comapny, Inc., pp. 551-554, 1941

[11]. ITT, Reference Data for Radio Engineers, Fifth Edition, Howard W. Sams and Company, inc. p. 22-23, 1974.

[12]. Johnson, W. C., op. cit. p. 78.

[13]. Dwight, H. B., Tables of Integrals and Other Mathematical Data, The Macmillian Company, p. 184, 1957.

[14]. Ramo, S., et.al., op. cit., p. 311.

[15]. Murdock, B. K., Handbook of Electronic Design and Analysis Procedure Using Programmable Calculators, Van Nostrund Reinhold Comapny, p 475, 1979.

[16]. Dwight, H. B., op. cit., p. 171.

[17]. King, R.W.P., op. cit, p.

[18]. Ramo, S., et.al., op. cit., p. 307.
[19]. Seely, S., Introduction on Electromagnetic Fields, McGraw Hill, pp. 185-186, 1958.

[20]. Burmeister, D., "Traffic Signal Detector Loop Location Design Installation," Illinois Department of Transportation, Division of Highways, District 6, p. 18, November 1, 1988.

[21]. Jefimenko, O.D., Electricity and Magnetism, Appleton Century Crafts, p. 372, 1966

[22]. Grover, F.W., Inductance Calculators: Working Formulas and Tables, Dover Publications, Inc., pp. 45-46, 1962.

[23]. Johnson, W. C., op. cit., p. 88.

[24]. Ibid., p. 105.

[25]. Dwight, H. B., op. cit., p. 144.

[26]. Mills, M. K., "Inductance Loop Detector Analysis, " 31st IEEE VTG Conference Record, p. 404, April 1981.

[27]. Grossner, N. R., Transformers for Electronic Circuits, McGraw Hill Book Company, pp. 176-177, 1967. 